\title{
PENGARUH LAMA FERMENTASI TERHADAP TOTAL ASAM CUKA AREN (Arenga pinnata Merr.)
}

\author{
Hesty Leasa ${ }^{1}$, M. Nur Matdoan² \\ ${ }^{1}$ Alumni Program Studi Pendidikan Biologi \\ ${ }^{2}$ Staf Pengajar Program Studi Pendidikan Biologi \\ E-mail: hesti_leasa@yahoo.co.id
}

\begin{abstract}
Background: Vinegar aren is one product that can be consumed also has many benefits for society. Palm vinegar is produced from palm juice that is fermented. The fermentation process that traditionally takes place at varying fermentation time make total acids in different palm vinegar. This study aimed to determine the effect on the total fermentation of palm vinegar.

Methods: The study was conducted at the Laboratory of Basic Chemistry Pattimura University in Ambon on 9 to 13 September 2014 with a long fermentation 2 days, 3 days, 4 days, 5 days, 6 days and analyzed using descriptive analysis.

Results: The results showed a significant influence, namely high total acetic acid contained in the fermentation 6 days is $4.56 \%$.

Conclusion: Long fermentation greatly affect the total vinegar palm juice. The influence that occurs is the increase in total acid levels with increasing palm vinegar fermentation.
\end{abstract}

Key Words: palm vinegar, fermentation, total acid.

\begin{abstract}
Abstrak
Latar Belakang: Cuka aren merupakan salah satu produk yang dapat dikonsumsi juga memiliki banyak manfaat bagi masyarakat. Cuka aren dihasilkan dari nira aren yang di fermentasikan. Proses fermentasi yang berlangsung secara tradisional dengan lama fermentasi yang bervariasi membuat total asam pada cuka aren berbeda-beda. Penelitian ini bertujuan untuk mengetahui pengaruh lama fermentasi terhadap total asam cuka aren.

Metode: Penelitian dilakukan di Laboratorium Kimia Dasar Universitas Pattimura Ambon pada tanggal 9-13 September 2014 dengan lama fermetasi 2 hari, 3 hari, 4 hari, 5 hari, 6 hari dan dianalisis menggunakan Analisis Deskriptif.

Hasil: Hasil penelitian menunjukan pengaruh yang sangat nyata yaitu total asam cuka yang tinggi terdapat pada lama fermentasi 6 hari yaitu 4,56\%.

Kesimpulan: Lama fermentasi sangat berpengaruh terhadap total asam cuka nira aren. Pengaruh yang terjadi yaitu adanya peningkatan kadar asam total cuka aren seiring dengan bertambahnya lama fermentasi.
\end{abstract}

Kata Kunci: cuka aren, lama fermentasi, total asam. 


\section{PENDAHULUAN}

Pohon aren atau enau (Arenga pinnata Merr.) cukup dikenal di kawasan tropik terutama di daerah Maluku. Hampir semua bagian fisik pohon ini dapat dimanfaatkan, misalnya akar (obat tradisional dan peralatan), batang (berbagai macam peralatan dan bangunan), daun muda (pengganti kertas rokok). Hasil produksinya juga dapat dimanfaatkan, misalnya buah aren muda (kolang-kaling), air nira (bahan pembuatan gula merah atau cuka), dan pati atau tepung dalam batang sebagai bahan pembuatan aneka makanan dan minuman. Selain itu tanaman aren juga dapat berfungsi sebagai tanaman konservasi tanah dan air (Saleh, 2004).

Menurut Barlina dan Lay (1994), produk-produk nira dapat digolongkan dalam dua kelompok, yaitu produk yang tidak mengalami proses fermentasi dan yang mengalami fermentasi. Nira adalah media yang subur untuk pertumbuhan mikroba seperti bakteri Acetobacter aceti dan sel khamir dari genus Saccharomyces. Pada nira yang mengalami fermentasi secara alami, sel khamir dari genus Saccharomyces akan lebih aktif untuk mensintesa gula (glokosa) dan menghasilkan alkohol dan gas $\mathrm{CO}_{2}$.

Produk fermentasi dari nira aren adalah arak, cuka, alkohol dan nata pinnata (Lempang, 2003). Cuka sebagai salah satu produk fermentasi tradisional yang dapat dibuat tanpa menggunakan biaya dan peralatan yang mahal. Salah satu cara pembuatan cuka secara alami dengan jalur biologis adalah cuka sageru.

Cuka aren adalah cuka yang dihasilkan dari nira aren yang di fermentasikan. Jika fermentasi nira aren berlangsung lebih lanjut, maka akan semakin banyak alkohol yang dihasilkan sehingga keasaman bahan tersebut meningkat. Pada saat keasaman nira aren meningkat, maka bakteri Acetobacter acetic akan lebih aktif untuk mengubah alkohol menjadi asam asetat sehingga keasaman nira aren akan semakin tinggi. Cuka aren dalam pembuatannya melibatkan proses fermentasi alkohol dan fermentasi asam asetat secara berkesinambungan (Syarief, 2009).

Cuka aren merupakan salah satu produk aren yang sudah dikenal sejak lama, selain sebagai produk yang dapat dikonsumsi juga memiliki banyak manfaat bagi masyarakat. Salah satu kandungan mineralnya adalah tembaga $(\mathrm{Cu})$ yang mempunyai peranan penting bagi manusia berkaitan dengan hemoglobin dimana kekurangan zat tersebut dapat menyebabkan berkurangnya ketahanan tubuh dan memicu meningkatnya kadar kolesterol (Intanwidya, 2005).

Cuka memiliki daya simpan yang lama disebabkan kandungan asetatnya. Sebanyak $0,1 \%$ asam asetat dapat menghambat pertumbuhan bakteri pembentuk spora penyebab keracunan makanan dan 0,3\% asam asetat dapat mencegah kapang penghasil metoksin, (Daulay dan Rahman, 1992). Apabila kadar alkohol $14 \%$ atau lebih akan terbentuk suatu lapisan yang akan menghambat proses fermentasi, sehingga tidak semua alkohol dapat diubah menjadi asam asetat. Bila kadar alkohol kurang dari 1 atau 2\% asam asetat yang terbentuk akan teroksidasi menjadi air dan karbondioksida, (Tyasning, 2006).

Menurut Waluyo (1984) mengatakan bahwa asam cuka aren selain digunakan sebagai bahan penyedap rasa, juga banyak digunakan sebagai bahan baku industri untuk memproduksi asam-asam alifatis terpenting. Asam cuka ini juga digunakan sebagai pengawet, untuk pembuatan obat-obatan (aspirin), pembuatan bahan pewarna (indigo) dan parfum serta disintesis menjadi aseton.

Larutan asam cuka yang dibuat secara fermentasi ini mempunyai keunggulan dibandingkan dengan produk asam cuka yang saat ini beredar di pasaran, karena mempunyai flavor yang lebih baik. Lama fermentasi sangat berpengaruh untuk menghasilkan kadar asam yang baik. Apabila proses fermentasi diteruskan, terlihat kecenderungan konsentrasi asam asetat menurun (Tyasning, 2006).

Untuk melihat konsentrasi asam asetat maka harus melakukan proses penentuan kadar asam asetat yang terdapat pada cuka aren. Salah satu cara untuk melihat kadar asam asetat yang terdapat dalam cuka aren yaitu dengan menggunakan penentuan nilai TAT (Total Asam Tertitrasi), (Sudarmadji dkk, 1997). 


\section{MATERI DAN METODE \\ Prosedur Penelitian}

Pengambilan sampel

Sampel diambil langsung dari tempat penyedapan di desa Hatu, sebanyak 5 liter. Pengambilan sampel dilakukan sebagai berikut:
a. Sebelum melakukan pengambilan sampel tangan dicuci bersih.
b. Dengan menggunakan tangan kanan, botol ditahan di bagian bawah, tangan kiri membuka kertas pembungkus botol.
c. Sampel dimasukkan dalam botol dengan cara menuangkan nira pada botol sampel.
d. Botol yang telah berisi sampel kemudian dimasukkan kedalam kotak, dan langsung dibawa ke laboratorium untuk memberikan perlakuan.

Tahap penyimpanan

a. Nira yang telah disadap diisi pada botol sampel.

b. Kemudian masing-masing wadah disimpan selama 2 hari, 3 hari, 4 hari, 5 hari, 6 hari.

c. Setiap interval waktu fermentasi selama penyimpanan dilakukan pengukuran kadar asam dengan metode TAT.

Penentuan nilai TAT (Total Asam Tertitrasi) (Sudarmadji dkk, 1997). a. Ditimbang sebanyak $10 \mathrm{ml}$ larutan cuka nira aren terfermentasi.

b. Dimasukkan ke dalam labu Erlenmeyer dan ditambahkan $100 \mathrm{~mL}$ aquades.

c. Dipipet sampel uji tersebut sebanyak $25 \mathrm{~mL}$ dan dimasukkan ke dalam labu Erlenmeyer lainnya.

d. Dititrasi sampel dengan larutan $\mathrm{NaOH}$ $0,1 \mathrm{~N}$ dengan menggunakan indikator phenolptalin (pp) sebanyak 2-3 tetes hingga berubah warna menjadi merah muda.

e. Dihitung jumlah total asam tertitrasiny dengan menggunakan rumus:

$$
\begin{aligned}
& \% \text { total asam }= \\
& \frac{\mathrm{Ml} \mathrm{NaOH} \times \mathrm{N} \mathrm{NaOH} \times \text { Grek }}{\text { Berat bahan }(\text { gram })}
\end{aligned}
$$

Keterangan:

Normalitas $(\mathrm{N}) \mathrm{NaOH} \quad: 0,1 \mathrm{~N}$

Grek asam asetat $\quad: 60$

Rancangan penelitian yang digunakan dalam penelitian ini adalah Rancangan Acak Lengkap Pola Non Faktorial dengan 5 perlakuan dan 3 ulangan.

\section{HASIL DAN PEMBAHASAN \\ Hasil \\ Diskripsi Hasil Penelitian}

Hasil penelitian analisa kadar asam asetat nira aren (Arenga pinnata MERR.) dapat dilihat pada tabel 1 sebagai berikut:

Tabel 4.1 Analisa Kadar Asam Cuka Aren (Arenga pinnata MERR.)

\begin{tabular}{cccccc}
\hline \multirow{2}{*}{ Perlakuan } & \multicolumn{3}{c}{ Ulangan } & \multirow{2}{*}{ Total } & \multirow{2}{*}{ Rata-Rata (\%) } \\
\cline { 2 - 4 } & $\mathbf{U}_{\mathbf{1}}$ & $\mathbf{U}_{\mathbf{2}}$ & $\mathbf{U}_{\mathbf{3}}$ & & \\
\hline $\mathrm{P}_{1}$ & 2,2922 & 2,3655 & 2,3348 & 6,9925 & 2,33 \\
$\mathrm{P}_{2}$ & 2,9373 & 2,9878 & 2,9072 & 8,8323 & 2,94 \\
$\mathrm{P}_{3}$ & 3,1353 & 3,2309 & 3,1939 & 9,5601 & 3,18 \\
$\mathrm{P}_{4}$ & 4,2340 & 4,0894 & 4,1363 & 12,4597 & 4,15 \\
$\mathrm{P}_{5}$ & 4,6009 & 4,5714 & 4,5372 & 13,7095 & 4,56 \\
\hline
\end{tabular}

Keterangan:

$\mathrm{P}_{1}=$ Lama fermentasi 2 hari

$\mathrm{P}_{2}=$ Lama fermentasi 3 hari

$\mathrm{P}_{3}=$ Lama fermentasi 4 hari

$\mathrm{P}_{4}=$ Lama fermentasi 5 hari

$\mathrm{P}_{5}=$ Lama fermentasi 6 hari 
Untuk selengkapnya dapat dilihat perbandingan rata-rata total asam cuka aren pada Grafik 1. Berdasarkan data pada Grafik 1 terlihat bahwa rata-rata total asam cuka nira aren (Arenga pinnata MERR.) yaitu lama fermentasi 2 hari 2,33\%, lama fermentasi 3 hari yaitu 2,94\%, lama fermentasi 4 hari yaitu 3,18\%, lama fermentasi 5 hari yaitu $4,15 \%$, lama fermentasi 6 hari yaitu $4,56 \%$.

\section{Total Asam Cuka Aren}

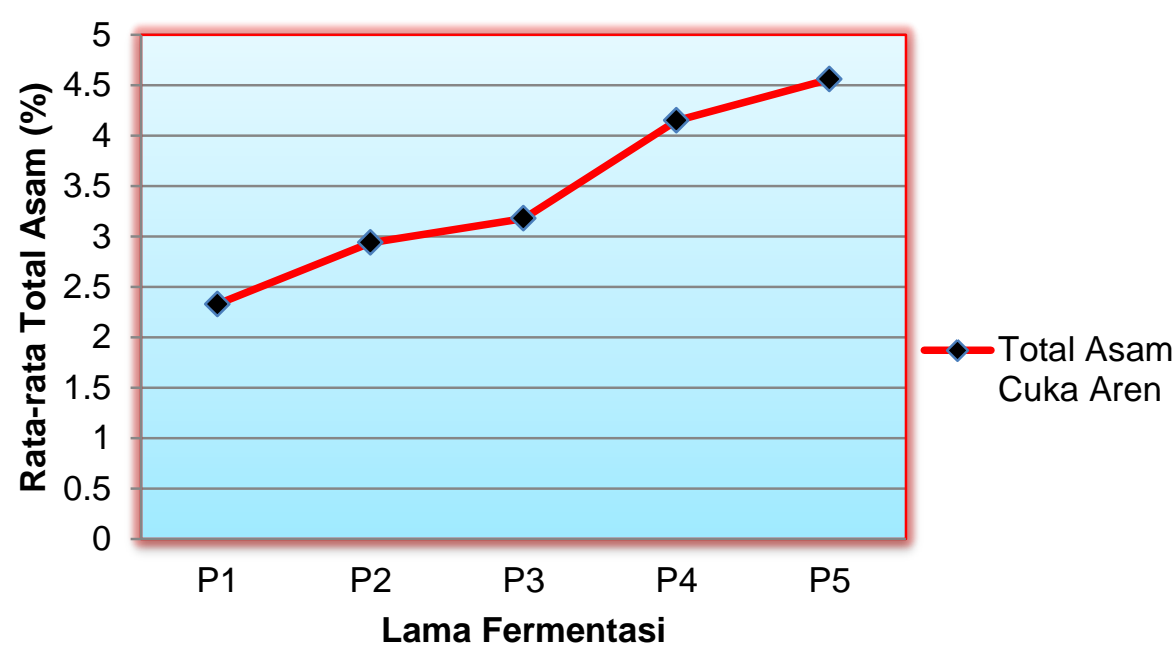

\section{Grafik 1. Perbandingan Rata-rata Total Asam Cuka Aren Berdasarkan Perlakuan Berbeda}

\section{Pembahasan}

Hasil penelitian menunjukan bahwa terjadi peningkatan kadar asam cuka aren pada setiap tindakan perlakuan berdasarkan lama fermentasi yang berbeda. Dari penelitian yang dilakukan dapat diketahui bahwa kadar asam yang rendah terdapat pada lama fermentasi 2 hari dengan kadar asamnya yaitu 2,33\% dan yang paling tinggi adalah lama fermentasi 6 hari dengan kadar asamnya yaitu 4,56\%. Syarief, (2009) mengemukakan bahwa pada fase ini mikroba banyak tumbuh dan membelah diri sehingga jumlahnya meningkat dengan cepat. Semakin lama waktu fermentasi maka Acetobacter aceti akan lebih aktif untuk mengubah alkohol menjadi asam asetat sehingga keasaman nira aren akan semakin tinggi, dalam pembuatan cuka melibatkan proses fermentasi alkohol dan fermentasi asam asetat secara berkesinambungan. Fermentasi asam cuka atau asam asetat pada dasarnya merupakan fermentasi lanjut produk fermentasi alkohol. Sebelum pembuatan cuka bahan baku yang digunakan yaitu nira aren tampak sedikit lebih kental namun setelah mengalami proses fermentasi menjadi cuka, bentuknya menjadi encer dan baunya sangat asam.).

Secara mikrobiologis bila alkohol kontak langsung dengan udara dan dibiarkan selama waktu tertentu akan berubah menjadi asam. Asam cuka dihasilkan oleh kegiatan Acetobacter aceti. Bakteri tersebut bersifat aerob dimana untuk mendapatkan energi, mikroba menggunakan glukosa atau zat organik lainnya sebagai substrat untuk dioksidasi menjadi karbondioksida dan air (Waluyo, 1984). Menurut Mappiratu dan Bakhri, (2013) tahap awal oksidasi alkohol akan dihasilkan asetatdehid dan tahap selanjutnya menjadi asam cuka atau asam asetat. Sunanto, (1992) juga 
mengemukakan jika proses fermentasi tuak dibiarkan dan berlangsung terus, akan terbentuk asam cuka yang rasanya asam. Menurut Daulay dan Rahman (1992) mengatakan bahwa cuka memiliki daya simpan yang lama disebabkan kandungan asetatnya. Asam asetat dapat menghambat pertumbuhan bakteri pembentuk spora penyebab keracunan makanan dan dapat mencegah kapang penghasil metoksin.

Salah satu faktor yang mempengaruhi fermentasi asam asetat yaitu lama fermentasi. Lama fermentasi akan mempengaruhi produk fermentasi yang dihasilkan. Waktu fermentasi yang terlalu pendek akan menghasilkan produk yang sedikit karena substrat tidak seluruhnya terdegradasi sedang waktu fermentasi yang terlalu lama, asam asetat akan teroksidasi menjadi karbon dioksida dan air. Oksidasi lanjut disebabkan karena substrat yang diubah kurang mencukupi sehingga bakteri Acetobacter aceti mencari alternative substrat lain sebagai energi untuk melakukan aktivitasnya yaitu dengan mengoksidasi asam asetat. Dalam proses fermentasi cuka aren apabila dibiarkan terus berjalan maka kadar asam asetat akan menurun. Hal ini disebabkan oleh asam asetat yang teroksidasi lebih lanjut menjadi $\mathrm{CO}_{2}$ dan $\mathrm{H}_{2} \mathrm{O}$. Pernyataan Muafi (2004) bahwa asam asetat melalui kondisi optimal pada waktu tertentu aktivitas bakteri sudah mulai berkurang seiring dengan berkurangnya substrat sehingga terjadi penurunan kadar asam asetat karena asam asetat telah dioksidasi lebih lanjut menjadi $\mathrm{CO}_{2}$ dan $\mathrm{H}_{2} \mathrm{O}$.

\section{KESIMPULAN}

Berdasarkan hasil penelitian yang dilakukan dapat disimpulkan bahwa lama fermentasi sangat berpengaruh terhadap total asam cuka nira aren. Pengaruh yang terjadi yaitu adanya peningkatan kadar asam total cuka aren seiring dengan bertambahnya lama fermentasi.

\section{DAFTAR PUSTAKA}

Afrianti. $2004.2 \quad$ Fermentasi. http://www.forumsains.com/index.php/t opic.783.msg2697. html diakses 22 oktober 2007.
Barlina R, Lay A. 1994. Pengolahan nira kelapa untuk produk fermentasi nata de coco, alcohol dan asam cuka. Jurnal Penelitian Kelapa Vol.7 No.2 Thn.1994. Balai Penelitian Kelapa, Manado.

Buckle, K. A, Edwards, R.A, Fleet, G.H. and Wooton, M. 1985. Ilmu Pangan. Jakarta. UI-Press.

Budiyanto, Moch. Agus Krisno. 2002. Mikrobiologi Terapan. Malang: Universitas Muhammadiyah Malang.

Campbell, N.A, Reece, JB, Mitchel, LG. 2002. Biologi. Jilid I. Jakarta: Erlangga.

Davis, Johnson. 1987. Nira dan Komposisinya. Jakarta.

Daulay, D dan A. Rahman.1992. Teknologi Fermentasi Sayur-Sayuran dan Buahbuahan. Bogor. IPB.

Effendi, D. S. 2010. Aren, Sumber Energi Alternatif. Warta Penelitian dan Pengembangan Pertanian. Tahun 2009.

Hidayati, N. 2009. Manfaat Pohon Aren. (http:/niahidayati.net). Diakses 20 Agustus 2010.

Intanwidya, Y. 2005. Analisa Cuka Dari Segi Kandungannya Berikut KhasiatnyaMasingmasing.http://www.mailarchive.com/for um@alumni akabogor. net/html.[23Desember 2009].

Ismanto, A. et al. 1995. Pohon Kehidupan: Aren (Arenga pinnata Merr.). Badan Pengelola Gedung Manggala Wanabakti dan Prosea Indonesia, Jakarta.

Kusumanto, D. 2010. Mencari Cara Pengawetan Alami Nira Aren untuk Produksi Gula Organik. (http://arenfoundation.wordpress.com). Diakses, 11 Agustus 2011.

Lempang, M. 2003. Pengolahan nira aren untuk produk fermentasi nata pinnata. Buletin Penelitian Kehutanan. Pusat Penelitian dan Pengembangan Teknologi Hasil Hutan, Bogor.

Lingga. A. 2008. Pengaruh Perbedaan Lama Penyimpanan Nira Terhadap Kadar Alkohol yang Dihasilkan. (http:/www.scribd.com). Diakses, 20 Oktober 2009. 
Lutony TL. 1993. Tanaman Sumber Pemanis. P.T Penebar Swadaya, Jakarta.

Naiola, E. 2008. Mikrobia Amilolitik pada Nira dan Laru dari Pulau Timor Nusa. Jakarta. (http://www.pdfchaser.com). Diaskses, 11 Februari 2011.

Mappiratu, dan Bakhri, S. 2013. Penuntuk Praktikum Bioteknologi. Jurusan Kimia Fakultas MIPA Universitas Tadulako. Palu.

Muafi, 2004. Muafi, K. 2004. Produksi asam asetat kasar dari jerami nangka. (kajian pengaruh penambahan sukrosa pada fermentasi alkoholik dan pengaruh konsentrasi starter dan lama fermentasi pada tahap fermentasi asam asetat). Skripsi MIPA. Jurusan Pertanian. Universitas Braijaya Malang. Malang.

Pelczar. M. J, Chan, E.C.S. 1988. Dasardasar Mikrobiologi. Jakarta: Universitas Indonesia Press.

Pratiwidan H. Alrasjid, 1989.Teknik Budidaya Aren. Departemen Kehutanan Badan Penelitian dan Pengembangan Kehutanan Pusat Penelitian dan Pengembangan Hutan. Bogor.

Ramadani P., I. Khaeruddin, A. Tjoadan I.F. Burhanuddin. 2008. Pengenalan Jenis-jenis Pohon yang Umum di Sulawesi. UNTAD Press, Palu.

Said, G, E. 1987. Bio industri. Mediatama Sarana Perkasa. Jakarta.

Saleh, M.S., 2004. Karakteristik Pohon Induk Aren di Kecamatan Biromaru Kabupaten Donggala. Hal.174-178. Proseding Seminar Pemanfaatan Sumberdaya Hayati Berkelanjutan, tanggal 28 September 2004 di Palu. Kerjasama UNTAD dan LIPI. Palu.

Soeseno, S. 2000. Bertanam Aren. Jakarta: Penebar Swadaya.

Sunanto, H. 1992. Aren: Budidaya dan Multiguna. Kanisius. Yogyakarta.

Sudarmadji, S, Haryono, B, dan Suhardi. 1997. Prosedur Untuk Bahan Makanan dan Pertanian. Liberty, Yogyakarta.

Syarief, 2009. Beda Cuka dan Khmir. http://halalsehat.com//journal/item. [14Januari 2010].

Tyasning, R. 2006. Pengaruh Pengadukan, Aerasi dan Konsentrasi Etanol pada Pembuatan Asam Asetat Dengan
Metoda Kultur Terendam. Skripsi. Jurusan Teknik Kimia. Universitas Lampung

Tjitrosoepomo, G. 2007. Taksonomi Tumbuhan Spermatophyta. Yoogyakarta: Gadjah Mada University Press.

Torar DJ, Kindangen JG. 1990. Pendapatan petani arak aren (kasus Desa Rumoong Atas, Sulawesi Utara). Buletin Balitka No. 10 Thn 1990 hal: 29-33. Balai Penelitian Kelapa, Manado.

Waluyo, S., 1984. Beberapa Aspek Tentang Pengolahan Vinegar, Jakarta. Dewi Ruci Press. 